\title{
Espelho, Espelho Meu! Que professor sou eu? Jnvestigando a identidade profissional de professores de língua na disciplina de Estágio Supervisionado em um curso de $\mathcal{L}$ icenciatura em Letras
}

\author{
Mirror, Mirror on the Wall! What kind of teacher am I? \\ INVESTIGATING THE PROFESSIONAL IDENTITY OF LANGUAGE TEACHERS \\ DURING THEIR SUPERVISED TEACHING PRACTICE IN A GRADUATION COURSE IN \\ Modern Languages
}

Selma Maria Abdalla Dias BARBOSA*
Patrícia Fabiana BEDRAN**

Resumo: Este artigo apresenta como principal objetivo compreender a identidade de um professor, em um contexto de formação inicial de professores, na disciplina Estágio Curricular Supervisionado, tendo como base teórica o conceito de identidade trazido pela literatura da área (NORTON, 2000; VARGHESE et al., 2005; LEFFA, 2012), aspectos cognitivos (ZEMBYLAS, 2005; BORG, 2009), bem como as emoções e a afetividade e sua relação com o processo de formação do professor (BARCELOS, 2004, 2007a, 2007b, 2013; ARAGÃO, 2005;

\footnotetext{
* Professora Adjunta da Universidade Federal do Tocantins (UFT); docente do Programa de Pós-Graduação em Ensino de Língua e Literatura (PPGL) e PROFLETRAS (Mestrado Profissional).Contato: selmaabdalla@uft.edu.br.

** Professora Assistente Doutora da Universidade Estadual Paulista "Júlio de Mesquita Filho” - UNESP/IBILCE. Responsável pela orientação e supervisão dos Estágios Curriculares Supervisonados em Língua Materna no Curso de Letras - Licenciatura da UNESP/IBILCE. Contato: bedran@ibilce.unesp.br.
} 
VIEIRA-ABRAHÃO, 2006a, 2006b; COELHO, 2011). Os resultados desta pesquisa qualitativa, de cunho etnográfico, que fez uso das narrativas como instrumento mediacional para e na formação professor (JOHNSON; GOLOMBEK, 2011), permitem visualizar a transitoriedade, complexidade e fluidez da(s) identidade(s) do participante, em um movimento contínuo de vai e vem, inter e intrarrelacionando-se por meio do discurso de fronteira, de forma híbrida e interdependente. Os resultados ainda evidenciam a necessidade de se abrir espaço na academia para se tratar de fatores emocionais, sociais e identitários, bem como a relevância da disciplina Estágio Curricular Supervisionado na formação da identidade do professor-aprendiz. Palavras-chave: Formação de professor. Identidade. Estágio Curricular Supervisionado.

Abstract: This article has as main objective to understand the identity of a teacher, in a context of initial training for teachers, during his supervised teaching practice subject, whose theoretical basis the concept of identity is brought from the literature area (NORTON, 2000; VARGHESE et al., 2005; LEFFA, 2012), cognitive aspects (ZEMBYLAS, 2005; BORG, 2009) as well as emotions and affection and their relationship with the teacher training process (BARCELOS, 2004, 2007a, 2007b, 2013; ARAGÃO, 2005; VIEIRA-ABRAHÃO, 2006; COELHO, 2011). The results of this qualitative research, ethnographic, which made use of narratives as mediational instrument for teacher training (JOHNSON; GOLOMBEK, 2011), let us see the transience, complexity and fluidity of the participant's identities, in a continuous movement back-and-forth, and intra-interrelationship through the border speech, hybrid and interdependently. The results also show the need to make room in the academy to deal with emotional, social and identity aspects of the pre-service teachers, as well as the relevance of the Supervised Teaching Practice subject in re-constructing the identity of the teacher-learner.

Keywords: Education of teacher. Identity. Supervised Teaching Practice.

\section{Introdução}

Muitas pesquisas têm investigado os problemas enfrentados pelo 
professor em início de carreira (GRANT; ZEICHNER, 1981; ROGERS; BABINSKI, 2002; ALSUP, 2006) e abordado a importância dos estágios na formação inicial dos professores (PIMENTA; GHEDIN, 2002) e, mesmo assim, ainda continua sendo desafiador esse período de experiência com a docência que, para muitos, acontece durante os estágios no curso de licenciatura em Letras. E seria justamente nesse período desafiador para o professor noviço que sua identidade profissional começa a ser delineada e ganha (novos) contornos.

Tendo em vista a dificuldade de lidar com a (re)construção e a (trans)formação de identidades, quando vivenciam a experiência prática no que se refere à docência, muitos professores rendem-se ao sistema de ensino encontrado nas escolas, mesmo que não compatível com as orientações e concepções pedagógicas que vivenciaram na universidade, bem como a identificações fixas e esteriotipadas dos professores, disseminada culturalmente, no meio social, como a de um professor branco, sexo feminino, classe média, com autoridade diante dos alunos e dom para ensinar.

Diante dessas questões, que evidenciam desafios encontrados pelos professores em formação inicial, torna-se relevante o estudo da(s) identidade(s) profissional(is) desses sujeitos, cuja carreira demanda muito mais do profissional do que se acreditava em tempos remotos, quando se pensava que qualquer pessoa estava apta a ensinar, bastando para tanto querer ou ter vocação. Hoje, porém, já se observa, por meio de diversas pesquisas que vêm sendo realizada na área, o quanto é complexo o sistema de ensino e aprendizagem de línguas e a formação de professores (ALMEIDA FILHO, 1993, 2014; VIEIRA-ABRAHÃO, 1996, 2006a, 2006b, 2014; GIL, 2005; CELANI, 2010; GERHARDT; AMORIM; CARVALHO, 2013).

Tendo em vista a (re)significação do papel do professor, diante do complexo processo educacional de ensinar e aprender, a identidade profissional, cultural e social de professores em formação inicial vem se tornando objeto de investigação de pesquisas nacionais (MOITA LOPES, 2002a, 20002b; CORACINI, 2003; GRIGOLETTO, 2003; FABRÍCIO, 2006; MAHER, 2006, 2010; RAJAGOPALAN, 2006; SIGNORINI, 2006; SILVA; MELO, 2010; REIS, 2011), bem como de estudos internacionais (NORTON, 2000, 2005; ALSUP, 2006; CLARKE, 2008; JOHNSON; GOLEMBEK, 2011). 
Por acreditar na relevância dessas pesquisas que buscam, por meio de diálogos interdisciplinares, esclarecer embates e jogos discursivos presentes na sala de aula, delineando as identidades profissionais, pessoais e culturais dos professores, objetivamos investigar, por meio da realização de uma pesquisa qualitativa de cunho etnográfico, as identidades que afloram ao longo do processo de formação inicial de dois professores-aprendizes de uma universidade pública federal, quando entram em contato com a experiência do estágio de docência, e como estas identidades se configuram e se (re)constroem, trazendo implicações para sua formação profissional.

Baseando-nos nos conceitos de identidade apresentados por Morgan (1994), Norton (2005) e Leffa (2012), estamos entendendo identidade profissional como essencialmente social, (re)negociada no e através do discurso/linguagem, na ação social, como também através de imagens que projetamos em nós mesmos e nos outros, bem como das imagens que os outros reconhecem em nós. No intuito de compreender a identidade dos participantes, tendo como foco a formação profissional, nos propusemos a considerar os aspectos cognitivos (ZEMBYLAS, 2005; BORG, 2009) e, também, as emoções e a afetividade (BARCELOS, 2004, 2007a, 2007b, 2013; ARAGÃO, 2005; VIEIRA-ABRAHÃO, 2006; COELHO, 2011) na (re)construção de identidades.

Partimos do pressuposto de que os professores-aprendizes não entram na academia prontos emocionalmente e decididos a se tornarem professores de línguas, bastando apenas a introdução e o contato com saberes científicos. É necessário criar espaços para explorar as identidades dos professores em sala de aula, em disciplinas que podem e devem contemplar essa temática, de forma a propiciar, aos professores em formação inicial, autoconhecimento e conscientização sobre sua identidade e sobre os fatores que estão diretamente relacionados a ela, o que, consequentemente contribui para a formação crítica e reflexiva desses futuros profissionais no que se refere à (re)construção de identidades e à sua atuação profissional nos diferentes contextos de ensino de línguas. 


\section{Identidade: concepções e reflexões no âmbito da formação do professor de língua}

A definição de identidade assumida neste trabalho tem como pressupostos os conceitos apresentados por Varghese et al. (2005), Norton (2000) e Leffa (2012). Para Norton (2000, p. 5), identidade é “o modo como uma pessoa compreende sua relação com o mundo, como essa relação é construída ao longo do tempo e do espaço, e como a pessoa compreende possibilidades para o futuro". Johnson (2006), por sua vez, acredita que identidade é "relacional, construída e alterada pela forma como eu vejo os outros e como eles me vêem em nossas experiências compartilhadas e interações negociadas" " e, nesta concepção, a autora introduz a visão do outro em relação à do eu-pessoal ou, ainda, contrasta o 'eu' versus o 'outro', dando vazão e significado ao que o outro traz para a negociação de identidades.

Leffa (2012) define identidade a partir de acepções contraditórias presentes no próprio termo e, para tanto, usa os adjetivos 'idênticos', quando a identidade significa igualdade, e 'identificável', quando o significado de identidade significa diferença. Nos termos do autor:

De um lado, significa a qualidade daquilo que não é diferente, daquilo que é o mesmo, igual, tal qual. Quando dois objetos, duas pessoas ou dois acontecimentos são totalmente iguais, sem nenhuma diferença entre si, podemos dizer que são idênticos. Por outro lado, identidade pode também significar o contrário, ou seja, aquilo que é diferente, exclusivo, não compartilhado pelo outro. A identidade de uma pessoa, por exemplo, é marcada por aquilo que a identifica, ou seja, por aquilo que a diferencia dos outros, incluindo traços físicos, posição social, preferências pessoais, idade, profissão, partido político, orientação sexual etc. (LEFFA, 2012, p. 54-55).

Nessa mesma perspectiva, Varghese et al. (2005), que apresentam uma visão mais focada na identidade do professor de línguas, define-a em termos

1 "Relational, constructed and altered by how I see others and how they see me in our shared experiences and negotiated interactions." 
das influências sobre professores, da forma como os indivíduos se veem e como legalizam sua profissão em suas configurações. Os autores compreendem identidade como "transformacional, transformadora, limitada ao contexto, e construída, mantida e negociada através da linguagem e do discurso" 2 . Entendemos, assim como Varghese et al. (2005), em consonância com os demais autores citados, que identidade não pode ser mais entendida como algo fixo, estável, unitário e coerente, mas, sim, múltipla, transitória, em conflito, transformacional e transformativa em sua essência e capacidade de agenciamento do ser humano; que não pode ser analisada isolada de um contexto social e histórico e, por fim, que as identidades são passíveis de (re)construções e (trans)formações ininterruptamente, em um processo contínuo de negociação de significados por meio do discurso.

Ao entendermos que as identidades são (re)construídas por meio dos discursos, faz-se necessário apresentarmos o conceito de discurso que norteou a elaboração deste trabalho. Tomando os devidos cuidados para não cunharmos uma definição rígida, unitária e inflexível de discurso, entendemos que discurso implica um modo de ação no mundo, assim como também significa uma expressão ou forma de representação desta ação social. Isto implica uma intrínseca relação constitutiva de linguagem e sociedade, entre a palavra e os múltiplos níveis: no nível do conhecimento e das crenças, no das relações sociais em comunidades, como, por exemplo, gênero, classe ou instituições, e também no nível das identidades sociais (FAIRCLOUGH, 1993; CLARKE, 2008). Em outros termos, ao mesmo tempo em que o homem produz e transforma o discurso, ele também é transformado através das constantes (re)negociações identitárias que ocorrem nas interações.

Essa definição de discurso tem como respaldo teórico uma perspectiva sociocultural (VIGOTSKI, 1987, 1999, 2010; JOHNSON, 2009). Sob tal perspectiva, a (re)construção de identidade se dá na relação do 'eu' com o 'outro' - social - nos contextos social, cultural e histórico em que o indivíduo está inserido, ou seja, em uma relação dialética entre o indivíduo e o social. O indivíduo a constrói e reconstrói em um processo contínuo de tornar-se

2 "Defined here in terms of the influences on teachers, how individuals see themselves, and how they enact their Professional in their settings". 
(MOITA LOPES, 2002a, 2002b). No âmbito da formação de professores, isso significa que o professor tende a se torna mais ativo e reflexivo, construindo conhecimento tendo em vista os contextos de ensino que vivencia e atua, ou seja, "os professores passam a ser vistos como aqueles que tomam decisões e constroem conhecimentos dentro de contextos particulares, com suas características sociais, culturais e históricas" (VIEIRA-ABRAHÃO, 2012, p. 460).

Nesse complexo processo, em que se busca compreender o sentido de ser professor de línguas, damos ênfase aos aspectos cognitivos e afetivos que influenciam a construção dessas identidades, o que significa abordar, também, crenças, pensamentos, experiências e emoções daqueles envolvidos nesse complexo processo (BARCELOS, 2007a; BORG, 2009; COELHO, 2011). De acordo com Borg (2009), não podemos compreender os professores e suas práticas sem que tenhamos entendido seus pensamentos, saberes e crenças, ou seja, há a necessidade de se voltar para a "vida mental dos professores" como uma contribuição significativa para a compreensão do processo de tornar-se, ser e sentir-se profissionalmente como professor.

'Crenças' estão sendo vistas, na perspectiva de Barcelos (2001), como formas de pensamentos, (re)construções da realidade, maneiras de perceber o mundo e que são passíveis de modificações diante de experiências práticas e teóricas, uma vez que se caracterizam pelo caráter dinâmico, paradoxal, contextual e social. Quanto à natureza das emoções, Moraes (2010, p. 159) afirma que se caracteriza como um corpo dinâmico de disposições de certas ações, o que significa que, em determinados domínios de certas emoções, tem-se a realização de alguns comportamentos e outros não. As crenças, associadas às emoções, apresentadas pelos professores em formação inicial, (re)constroem identidades e tendem a influenciar suas atitudes como professores, assim como as crenças são influenciadas pelas ações dos professores e pela construção de identidade, em um processo de influências múltiplas.

Quando os professores vivenciam experiências positivas no ensino de línguas e em sua formação - lembranças e emoções prazerosas - ou negativas - neste caso, quando trazem em 'suas vidas mentais' experiências e/ou emoções frustrantes, embaraçosas e inapropriadas, como um processo de ensino e aprendizagem descontextualizado, irreal e passivo -, essas diferentes 
experiências dão origem a crenças diversas que tendem a influenciar, positiva ou negativamente, a prática desses futuros professores e a construção de suas identidades, em um processo bidirecional.

Diante disso, seria o caso de nos questionarmos, então, sobre a possibilidade e os caminhos para potencializar e otimizar as ações-emoções dos futuros professores de língua, promovendo interações que propiciem um clima positivo e agradável em sala, que os motivem a criar um ambiente desejável, de amor e respeito (MATURANA, 2005) e/ou, ainda, de despertar sentimentos de pertencimento ao grupo e de promover atividades significativas e situadas de ensino, condizentes com as necessidades e as práticas reais vivenciadas pelos professores-aprendizes em suas experiências em estágios de docência.

Um caminho para viabilizar e ampliar o desenvolvimento de práticas que contemplem interações como as descritas anteriormente seria buscar a elaboração e o respaldo em currículos e ementas mais flexíveis nos cursos de formação de professores, principalmente nas disciplinas que visam a formação do professor, como as de Estágios Curriculares Supervisionados, de forma a propiciar aos professores-formadores, professores em formação e professores das escolas campo de estágio, mais oportunidades para discutirem propostas existentes e criarem outras novas, contemplando tanto uma formação mais autônoma dos professores em formação, como, também, abrindo espaço nas academias para discursos mais subjetivos e humanos, como os que falam de amor, respeito mútuo, sentimentos, emoções, crenças e negociações identitárias.

Nesse sentido, compartilhamos das ideias de Rosiek (2003, p. 399), de que realmente "é angustiante que nos encontremos em um momento em que o discurso público sobre a educação seja tão exclusivamente focado em resultados cognitivos e mensuráveis de ensino" ". Em outros termos, diríamos que nos encontramos em um momento situadamente histórico de formação de professores, que prioriza o conhecimento científico em detrimento de uma formação profissional voltada para o desenvolvimento emocional e de

\footnotetext{
3 "It is distressing, therefore, that we find ourselves in a moment when the public discourse about education is so exclusively focused on measurable cognitive otucomes of teaching".
} 
negociações identitárias, quando, conforme aponta Rosiek (2003), toda experiência humana está intrinsecamente relacionada aos aspectos sentimentais e emocionais.

A experiência humana é um caso emocional. Isto é tão verdadeiro para as experiências educacionais como o é para qualquer outro aspecto de nossas vidas. A aprendizagem não é simplesmente compreender sobre o conteúdo abstrato de idéias, é sobre a descoberta de nós mesmos em relação a novas idéias. Isto envolve surpresa, revelação, prazer, e às vezes indignação (ROSIEK, 2003, p. 399).

Nessa mesma perspectiva, entendemos que as atividades e experiências prático-teóricas educacionais dos professores em formação não devem ser refletidas e analisadas separadamente dos aspectos emocionais e das negociações identitárias. Ao compreender e abordar de forma dialética e dialógica a (re)construção de identidade profissional desses professores, tendo em vista os aspectos emocionais, o formador necessita estabelecer uma relação imbricada entre teoria e prática, levando em consideração as práticas sociais tanto dentro como fora da sala de aula, que apontam para embates culturais, sociais, políticos, filosóficos e ideológicos que fazem parte do complexo processo de formar, ser, sentir-se a atuar como professor.

\section{Narrativas como Ferramentas Catalisadoras}

No complexo processo de formação de professores, as narrativas podem configurar-se como um tipo textual potencializador de instâncias crítico-reflexivas, colaborativas e conscientizadoras de conhecimentos. De acordo com Scherer, Morales e Lecrerq (2003, p. 25), narrar “não é unicamente enunciar dados (idade, formação, sexo, escola) para construir fatos, mas é falar ao outro", é fazer sentido para o outro e, ao fazermos sentido para o outro, estamos, ao mesmo tempo, tentando encontrar apoio ou discordância no que falamos para nos identificarmos e nos (re)afirmarmos como o 'eu' criador daquele discurso identitário em contraste com o outroprofessor observado na escola campo de estágio, formador, alunos, colegas e outros - produzido por meio da linguagem. 
Johnson e Golombek (2011) apresentam três funções básicas para a narrativa: externalização, verbalização e reflexão sistemática. A primeira função, externalização, serve para que professores ampliem seus conhecimento e sentimentos pela (re)ação, criando oportunidades para introspeção, explanação e construção de significados. Em outras palavras, por meio das narrativas, os professores se veem capazes de reconhecerem seus pensamentos, suas crenças, seus conhecimentos, medos e esperanças de forma explícita, estabelecendo, assim, coesão no que pode parecer desconexo, em uma tentativa de articular questões e problemas enfrentados na experiência da docência com sua identidade profissional.

A segunda função da narrativa, a verbalização, funciona como uma ferramenta que auxilia o narrador não apenas a pensar e reconhecer seus pensamentos, as teorias estudadas, as práticas de ensinar e aprender língua, mas, também, a internalização do conhecimento ou, como afirmam Johnson e Golombek (2011), representa a regulação do processo de pensar, ou seja, "o que distingue a narrativa como verbalização é o uso intencional de conceitos científicos ${ }^{[4]}$ como ferramentas para o entendimento, ou pensar em conceitos, entendida como resultado e também evidências da internalização" (JOHNSON; GOLOMBEK, 2011, p. 7) ${ }^{5}$.

A narrativa como instrumento de reflexão sistemática, terceira função, seria usada por professores como objeto de investigação e pesquisa pensando em seu próprio desenvolvimento profissional. Quando os professores em formação se encontram engajados na atividade de escrita das narrativas, eles tendem a se engajar em uma atividade que propiciará o mapeamento de sua própria aprendizagem, uma vez que se trata de uma atividade que requer reflexão e análise crítica de sua experiência e relação dessas experiências com a literatura da área.

Em suma, as narrativas podem funcionar como instrumento mediacional do processo de formação do professor, uma vez que permitem

4 'Conceito científico' está sendo compreendido a partir de uma perspectiva sociocultural, conforme abordado por Vigotski (1986).

5 "What distinguishes narrative as verbalization is the intencional use of scientific concepts as tools for understanding, or thinking in concepts, understood as both an outcome of and of and evidence for internalization". 
a ele engajar-se em uma prática social catalisadora de (re)negociação de sua identidade profissional. Ao narrarem, os professores não somente verbalizam seus pensamentos, mas também são conduzidos a se autoconhecerem melhor, a articularem saberes científicos e cotidianos, a refletirem sistematicamente sobre todos esses aspectos, por meio de uma relação imbricada entre teorias e prática, de forma situada, levando a (re)construções teóricas, práticas e identitárias, de forma situada social e historicamente.

\section{Metodologia de Investigação}

Trata-se de uma pesquisa qualitativa (MOITA LOPES, 1996), interpretativista (ERICKON, 1986; ANDRÉ, 2000, 2005) e de cunho etnográfico, em que acompanhamos o complexo processo de transitoriedade e desenvolvimento de identidade profissional de professores em formação inicial, professores-aprendizes, durante quatro semestres, isto é, quatro períodos letivos, tendo como contexto as disciplinas semestrais Investigação da Prática Pedagógica e Estágio Supervisionado em Língua Inglesa: Língua e Literatura I, II, III e IV.

No recorte deste artigo, focalizaremos um participante - Benjamin, 20 anos, matriculado regularmente no curso de Licenciatura em Letras de uma universidade federal. Benjamin nunca havia ministrado aulas de inglês antes da realização do estágio no curso de Licenciatura, cursou o ensino médio em uma escola pública e nunca fez curso de inglês em escolas particulares de idiomas.

Como instrumentos de pesquisa utilizamos as narrativas das experiências de docência do estagiário, que observava e ministrava aulas na escola campo de estágio. Essas narrativas compuseram os relatórios de estágio e foram avaliadas nas disciplinas semestrais de Estágio Curricular Supervisionado. Os relatórios foram produzidos no decorrer de quatro semestres: I $\left(5^{\circ}\right.$ Período - Relatório I), II (6 $6^{\circ}$ Período - Relatório II), III ( $7^{\circ}$ Período Relatório III) e IV ( $8^{\circ}$ Período - Relatório IV), totalizando dois anos (2010 e 2011) de coleta de dados. No $5^{\circ}$ Período (Relatório I), os professoresaprendizes realizaram apenas estágio de observação de aulas e, nos demais períodos, desenvolveram estágio de regência de aulas. 
Em convergência com os apontamentos de Silva e Melo (2010, p. 134), que criticam o fato de os relatórios, em grande parte dos contextos, restringirem-se à narração e à descrição da rotina das unidades escolares onde são realizados os estágios, acrescento que as narrativas que compõem os relatórios e serviram de instrumentos para essa pesquisa trazem, em seu bojo, estilos ímpares de escritas, relevantes para a análise e configuração de identidades profissionais com autorreflexões dialéticas e dialógicas, orientada e mediada pelos formadores, propulsoras de um desenvolvimento profissional mais autônomo e subjetivo, tendo em vista o objetivo das disciplinas de formar professores mais críticos, reflexivos e autônomos.

Além das narrativas, utilizamos também, como instrumentos de pesquisa, o fórum de discussão da plataforma acadêmica Moodle e o registro de sessão temática. O fórum funcionava como um ambiente de complementação das atividades realizadas em sala e de reflexão sobre as atividades de estágio. O registro da gravação em vídeo de três sessões temáticas - realizadas entre formador e professores em formação, assim nomeadas: 1) Tornar-se professor ( $5^{\circ}$ Período); 2$)$ Ser professor ( $7^{\circ}$ Período); e 3) Sentir-se professor ( $8^{\circ}$ Período $)$ - tinha como objetivo promover discussões mais pontuais sobre a prática de estágio vivenciada pelos professores em formação, tendo como respaldo a teoria trabalhada na disciplina durante o semestre. Nessas sessões, mediadas pelo formador, os alunos puderam fazer comparações, levantar questionamentos, emitir opiniões, sugestões e reflexões sobre a própria formação e as experiências realizadas.

\section{Análise dos Dados}

Podemos identificar, ao longo da análise, quatro categorias que denotaram a construção de identidade profissional de Benjamin, as quais foram recorrentes na categorização dos dados: a identidade de aluno/ aprendiz, a identidade de professor em formação, a identidade de professor de língua inglesa e a identidade sociocultural. Todas elas apresentam-se de forma oscilante, provisória e fluida, conforme veremos na discussão realizada a seguir.

A transitoriedade da identidade de aluno/aprendiz para a identidade de professor pode ser visualizada na narrativa de Benjamin ao realizar uma 
reflexão sobre o que foi aprendido na experiência de estágio, em que a supervisora (formadora) esteve presente durante a aula ministrada por ele e, posteriormente, sobre o feedback proporcionado. $\mathrm{Na}$ sua identidade de aluno aprendiz, Benjamin demonstra insatisfação quanto à forma de avaliação e à nota atribuída pela supervisora de estágio, conforme podemos observar no excerto que segue.

\section{Excerto 1}

Bejamin: A turma era/é indisciplinada, os alunos se espancavam dentro da sala de aula, falavam palavrões, conversavam, enfim, era impraticável. De fato, mudamos o comportamento da turma, mas o professor não dispõe de tais informações para embasar seu julgamento, o que compromete a coerência da avaliação, além do fato de nossas atuações variarem, sendo em alguns dias próximas da perfeição e em outras um fiasco (Relatório de Estágio III).

No Excerto 1, Benjamin demonstra um acentuado desenvolvimento de sua identidade profissional ao reconhecer a imprevisibilidade de uma aula, mesmo sendo minuciosamente planejada. Sendo assim, assume que os resultados sofrem influências variadas, tanto de fatores internos quanto externos à sala de aula, como a motivação do professor e/ou do aprendiz, as experiências e emoções específicas daquele momento ímpar de atuação e interação entre professor-estagiário, aluno, supervisor e outros.

$\mathrm{Na}$ primeira sessão temática, durante o período de estágio de observação de aula, podemos observar a transitoriedade da identidade de aluno/aprendiz para a identidade de professor de inglês, porém, realizada de maneira muito mais tensa. Benjamin assume um papel de rejeição à imagem de professor de língua inglesa, tornando a negociação do EU-profissional com o EU-pessoal bem mais conflituosa (ALSUP, 2006), isto é, ele não se vê como tal ou, ainda, não deseja assumir essa nova identidade. 


\section{Excerto 2}

Benjamin: Ah! Sim porque eu não pretendo dar aula de inglês? Eu não quero ser professor de inglês! Professora, deixa eu explicar porque eu não pretendo dar aula de inglês, até posso mudar ou amadurecer minha ideia, mas hoje dentro do estágio eu não acredito no professor de inglês! Por quê? Porque eu não acredito no ensino de inglês, a verdade é essa! Se eu acreditar eu passo a dar aula de inglês! Ah não! Sim, aí que tá! Eu sou oito ou oitenta, né? Eu não sou do tipo que discurso uma coisa e faço outra. Eu não sou! Então assim, eu não me vejo hoje apto a dar uma aula de inglês como deveria ser dada de inglês e diante dos alunos não me sinto confortável com a situação (Sessão 1, março de 2010 - ênfase nossa).

Para que ocorra uma negociação mais pacífica entre a posição do EU-pessoal com o EU-profissional, Benjamin se impõe duas condições, conforme mostra o Excerto 2: "acreditar no professor e no ensino de língua inglesa”, como também "estar apto a dar aulas de língua inglesa como deveria ser dada". Apoiando-nos em Leffa (2012), justificamos a questão da negociação da diferença do EU versus o OUTRO tendo como base o pressuposto de que "o indivíduo resiste, negocia, muda e transforma, a si e ao outro” (PAVLENKO; BLACKEDGE, 2004 apud LEFFA, 2012, p. 72). É esta possibilidade de transformação do sujeito durante o processo de negociação de identidades que justifica o interesse/motivação pelo seu estudo de identidades (NORTON, 2000).

Em contraponto com essa tensão inicial, relacionada à resistência de se ver e se entender como professor, posteriormente, no último período ( $4^{\circ}$ Período) de realização de estágio, Benjamin apresenta uma identidade de professor bastante desenvolvida e holística - isso pode ser percebido quando se coloca diante do OUTRO social, confessando suas mudanças subjetivas ou, ainda, contrastando a mudança do seu EU versus o OUTRO social, representado aqui pelos políticos e governantes responsáveis pelas leis que regem a educação brasileira, o sistema educacional, bem como por diretores, coordenadores, secretários, entre outros, ou seja: a comunidade social que envolve o processo educacional. Vejamos a seguir: 


\section{Excerto 3}

Benjamin: O contato com a educação pela perspectiva de professor altera profundamente a maneira que sentimos e percebemos a sociedade e interfere de forma decisiva nos processos sociais em que estamos envolvidos. Creio que posso tecer tais críticas por buscar vivenciar o que defendo, e tenho ciência de que ainda estou a atingir meus próprios objetivos por isso não pretendo desistir de progredir e ajudar a fazer uma diferença positiva a cada aula (Relatório de Estágio IV - ênfase nossa).

É necessário ainda ressaltar o desenvolvimento de sua identidade profissional quando nos mostra que tem consciência de que essa identidade será um eterno 'tornar-se', um (re)fazer-se em futuras negociações de seu EU-pessoal versus seu EU-profissional, ao dizer "tenho ciência de que ainda estou a atingir". Nessa perspectiva, Moita Lopes e Bastos (2002, p. 9) descrevem a importância do tornar-se, como um projeto de vida em que nos engajamos e que nos move a "ambicionar refletir sobre a vida social", tentar compreendê-la, ao mesmo tempo em que "sinaliza novas configurações sobre quem somos ou podemos ser".

O contato com a educação foi possibilitado por meio da experiência de estágio de regência e de observação de aula, que permite ao professor engajar-se em discursos de fronteira não apenas com relação à sua identidade profissional, mas também por meio de negociações de identidade de aluno aprendiz/acadêmico, pesquisador e de professor estagiário, como podemos visualizar no excerto logo a seguir.

\section{Excerto 4}

Benjamin: O estágio supervisionado é um dos momentos de maior desafio durante nossa formação. Eu, mesmo trabalhando com pesquisa através de iniciação científica (com um orientador que trabalha com estágio), me sinto bastante preocupado com as regências e consideroas um desafio enorme, pois saio da posição de aluno e pesquisador (papéis em que não sinto tanta pressão) para a posição de professor, 
em que estou sendo testado e avaliado não só pelo formador da faculdade, mas pelos alunos e equipe pedagógica da escola em que estagio (Relatório de Estágio II).

No Excerto 4, Benjamin, em uma troca assimétrica de posições de poder (NORTON, 2000) e papéis, sente-se tenso ou até mesmo amedrontado com a nova identidade que terá de assumir: a de professor em formação inicial. Ele se mostra ciente de que, como professor estagiário, terá de passar por situações muitas vezes constrangedoras, conflituosas ou de submissão, por ser avaliado não só pelo professor formador, mas também pelo professor regente e pela equipe pedagógica da escola-campo.

Convém ressaltarmos a presença das emoções - pressão, medo e/ou receio - que perpassam o processo de (re)construção de identidade profissional. Corroborando os apontamentos de Coelho (2011, p. 37-38), de que "a busca de uma identidade profissional própria está intrinsecamente ligada às histórias pessoais de cada professor e, por consequência, às suas emoções", ressaltamos a necessidade de compreender e reconhecer o papel das emoções e das histórias de vida dos professores no processo de formação dos alunos, que está associada à sua identidade sociocultural, compreendida a partir de uma perspectiva ontológica e/ou contextual, geográfica e histórica dos participantes.

Com relação à identidade sociocultural, Benjamin assume uma perspectiva crítica e reflexiva, o que gera uma preocupação em assumir uma identidade de professor de língua inglesa consciente de seu papel social e cultural, como mostrado no excerto que segue.

\section{Excerto 5}

Benjamin: Não me venham dizer que o inglês é indispensável ao aluno da Karla que disse 'eu moro no Raizal', porque não o é! Creio que um segundo idioma é apenas mais uma ferramenta para a abertura de novos horizontes (culturais, experienciais etc.), assim como as artes, formação profissional [...]. Não acho que devemos convencer nossos alunos de que o Inglês será a boia de salvação que lhe oferecemos para lhe tirar da areia movediça de suas realidades: eles não são bestas, 
e perderão a confiança em nós. Mas se, por outro lado, conscientizarmos os alunos de que o Inglês é uma ferramenta que deve ser aliada a outras tantas para descobrir o mundo e modificá-lo, então ganharemos não só confiança, mas respeito dos alunos (novembro de 2010).

A concepção de que a aprendizagem e o ensino devem ser motivados por questões políticas, sociais e econômicas está associada à identidade sociocultural-ontológica de Benjamin. O professor-aprendiz, por fazer parte de uma comunidade social de baixa renda de 'uma família que veio do sertão' e teve que vencer várias batalhas como analfabetismo, pobreza, subnutrição, dentre outras, coloca-se em uma posição de guerra e batalha, precisando constantemente estar munido de ferramentas poderosas, como o conhecimento da língua inglesa, como forma de subversão ao sistema em que vive ou, ainda, como forma de defesa em relação ao OUTRO colonizador, manipulador e ameaçador (LEFFA, 2012), representado no falante nativo de língua inglesa.

\section{Excerto 6}

Benjamin: Então, eu vejo todos aqueles edifícios e monumentos a monarquia e vejo quantos passaram fome e foram mortos para ostentar isso. Eu uso o inglês como forma de subversão, né! Como forma de virar o jogo. Eu nasci para ser um desgraçado na vida! Eu nasci num país subdesenvolvido, numa família que veio do sertão, meu avô e avó são analfabetos. Então, assim, minha mãe tinha a sétima série e me alfabetizou (Sessão Temática 3).

Estudos realizados por Leffa (2012) sobre a (re)construção de identidade do século XXI nos apresenta três dimensões de identidade: 1) geográfica, com ênfase no eixo espacial; 2) histórica, com ênfase no eixo cronológico; e 3) dialética, com ênfase na diferença do outro. Recorremos a esta última neste momento pontual, ao abordarmos o Excerto 6. Nele, Benjamin sinaliza estar consciente das diferenças entre o seu EU e o OUTRO - falante de língua inglesa, ou seja, ele sabe o que o outro não é porque 
pertence a uma comunidade diferente, na qual teve de 'lutar' contra um sistema que preconiza a desigualdade econômica e social como forma natural proveniente de uma política democrática, neoliberal, capitalista e consumista.

Essa trajetória, responsável pela construção da identidade sociocultural de Benjamin, possivelmente contribui com a rejeição em ser professor de língua inglesa, como um reflexo de rejeição à língua inglesa do 'outro', colonizador e imperialista, em uma relação de superioridade e poder ao EU-falante de língua materna. Ademais, Benjamin reflete na figura do professor de inglês, o OUTRO, o 'the teacher', ameaçador, como mostra o Excerto 7, a seguir. Isso tem relação com a postura real de muitos professores que, de acordo com Moita Lopes (1996, p. 38), perpetuam discursos imperialistas e a superioridade do falante nativo quando afirma, por exemplo, que se sentem "melhor falando inglês do que português".

\section{Excerto 7}

Benjamin: eu vejo hoje o professor de inglês com muita hipocrisia, dizendo que o professor é THE TEACHER é o bambam e tal o bonzão e ninguém faz nada para mudar a situação (Sessão Temática I).

Por outro lado, ao vivenciar o estágio de regência, Benjamin se entusiasma com os resultados imediatos das primeiras aulas, em que sugere um trabalho interdisciplinar com as turmas, no qual os alunos teriam de apresentar peças teatrais ou grupos musicais interpretando, em inglês, suas falas. Diante dessa experiência, Benjamin, ao expressar contentamento, mesmo que em uma fluidez precipitada de três dias em que ocorreu tudo como planejado, sente-se e projeta-se na imagem de um professor de língua inglesa, em uma contínua (re)negociação de seu EU-pessoal e o EU-profissional por meio do discurso de fronteira. De fato, ele mostra uma identidade de professor crítico-reflexivo e preocupado com o objetivo a ser alcançado na preparação e desenvolvimento de um projeto. 


\section{Excerto 8}

Benjamin: me arrisco a dizer, ministrei a melhor aula dentre todos os estágios - inclusive considerando a língua materna. Estávamos vivendo o sonho de uma prática irretocável durante, pelo menos, três aulas. Já podíamos visualizar os relatórios contendo resultados brilhantes, sendo encaminhados para se tornarem artigos, mas o que temos é um relatório que funciona como uma espécie de 'muro das lamentações', em que prostramos para confessar nossos pecados, implorando por qualquer tipo de intercessão divina que nos salve dos apuros de sermos professores (Relatório de Estágio III - ênfase nossa).

Logo em seguida, conforme relatado no Excerto 8, Benjamin sofre as frustrações com resultados negativos de seu projeto, sobre os quais incidiram fatores internos e externos à sala de aula, como podemos visualizar no excerto seguinte.

\section{Excerto 9}

Benjamin: Durante nosso estágio houve diversos acontecimentos que contribuíram significativamente para o fracasso do projeto. Além dos problemas já citados, houve quatro trocas de professores de inglês só nas turmas que estávamos estagiando, além da mudança de diretoria, coordenação, horários (mudaram três vezes). Além disso, roubaram minha motocicleta (meu único meio de transporte) na porta da escola, por volta das $14 \mathrm{~h}$, após uma aula de inglês. Quase fiquei em estado de choque, pois estou cursando 40 créditos na faculdade esse período, tendo aulas praticamente todos os dias pela manhã e à noite, além dos estágios à tarde. Eu moro no bairro JK, no extremo oposto da cidade em relação ao campus da faculdade e da escola que estagiei, sendo o uso do ônibus inviável. Juntei todas as minhas economias que estavam sendo reservadas para o mestrado em Campinas, minha mãe fez um empréstimo no banco e comprei uma moto (Relatório de Estágio III). 
O Excerto 9 permite repensar como as emoções e as experiências, positivas e negativas (BARCELOS, 2004, 2006, 2013b; MORAES, 2010), influenciam as decisões do professor em formação. Benjamin, após sofrer várias experiências negativas e vivenciar sentimentos de frustração e impotência diante de uma realidade educacional repleta de falhas e problemas, tanto interno quanto externo ao seu sistema, deixa transparecer que, em sua negociação identitária com seu Eu-profissional e do seu Eu-pessoal, predominou a não motivação em prosseguir na (re)construção de sua identidade profissional e, principalmente, na sua identidade de professor de língua inglesa.

Porém, na sua narrativa do Relatório de Estágio IV, o participante reconhece seu processo de evolução e amadurecimento que ocorreu durante os quatro últimos semestres em que realizou a disciplina de estágio supervisionado e as regências de aulas, se sentindo mais autoconfiante em ministrar aulas, principalmente a de língua inglesa. Tem-se, assim, um processo de negociação de identidade, uma vez que, em diversos momentos, no período I e II, como mostrado no Excerto 2, Benjamin sente-se inseguro e 'não apto’ para exercer a prática docente.

\section{Excerto 10}

Benjamin: Neste último período de estágio pude desfrutar do amadurecimento pelo qual passei nos semestres anteriores e pude desenvolver minhas atividades de maneira totalmente confortável, me sentindo apto a dominar e direcionar as turmas às quais me dediquei (Relatório de Estágio IV).

A disciplina de Estágio torna-se fundamental para o processo de construção identitária, como se agisse como um divisor de águas. Benjamin, no início, era totalmente descrente com relação à possibilidade de vir a se tornar professor de língua estrangeira, mas, depois de vivenciar as experiências de sala de aula, decidiu-se por ser professor de línguas - materna e estrangeira -, contrasta com OUTROS que entraram no curso de Letras decididos a serem professores de línguas e, no entanto, depois de se deparar com as dificuldades da sala de aula, desistiram. Em seus termos: 


\section{Excerto 11}

Benjamin: É engraçado quando pensamos nisso, porque quatro anos é muito tempo. Hoje formandos, é engraçado lembrar-se de nossas expectativas e sonhos ao ingressar no curso de Letras (alguns não sabiam que era pra ser professor. Eu sabia, mas não pensava nisso). E ver que a maioria deles se transformou a partir dos estágios. Muitos de nós queríamos ser professores, houvesse o que houvesse e ficaram extremamente frustrados com a sala de aula. Outros (estou nesse grupo) eram totalmente descrentes em relação à possibilidade de virem a se tornarem professores e, nas dificuldades enfrentadas durante o estágio, decidiram que tentariam interferir da melhor maneira possível na educação (Fórum do Moodle - setembro de 2011).

O estágio configura-se como uma instância crucial e propulsora da passagem e/ou negociação de sua identidade de professor-estagiário para professor de línguas. Isto nos leva a entender a importância da disciplina de estágio supervisionado curricular na construção e no desenvolvimento da identidade do professor em formação inicial. Os momentos e circunstâncias em que houve maior negociação de identidades pessoais e profissionais esteve relacionado às experiências vividas na e com a disciplina em questão, posto que tais experiências podem ser instigadoras de (trans)form(ação) de sonhos e expectativas no que se refere à prática docente.

\section{Considerações Finais}

Os resultados da presente pesquisa permitem evidenciar uma interligação de fatores sociais, cognitivos e emocionais de (re)construção identitária do professor-aprendiz Benjamin. Por meio das narrativas, pudemos visualizar sincronicamente o complexo processo de (re)construção de identidades, bem como transitoriedade dessas identidades. As identidades, de aluno/aprendiz, de professor em formação, de professor de língua inglesa, bem como a sociocultural, configuram-se de forma transitória, em um movimento contínuo de vai e vem, inter e intrarrelacionando-se por meio do discurso de fronteira, de forma híbrida e interdependente. 
Pautando-nos no conceito de discurso de fronteira (borderland discourse) abordado por Alsup (2006), podemos observar que o professor-aprendiz engaja-se em negociações entre o EU-pessoal e o Eu-profissional, tornandose apto a se mover da identidade de aluno para a de professor. Isso não acontece pela simples imitação de modelos culturais impostos e estagnados na sociedade, mas, sim, pela transformação significativa de seus self, em um complexo e dinâmico processo de transitoriedade de identidades.

Os discursos de fronteira, que se deram de maneira tensa e conflituosa, foram responsáveis pela (re)construção e (trans)formação de sua identidade profissional. Mesmo se mantendo firme na recusa em ser professor de língua inglesa, ao término do curso de graduação, Benjamin desenvolveu sua identidade de professor de línguas. Essa movimentação e essa (re)construção identitária foram perpassadas por momentos emocionais e experienciais que o participante traz em seus selves e tendem a ser positivos ou negativos em uma dada circunstância.

Crenças, paixões e ideologias influenciaram e ajudaram na construção da identidade do futuro professor e, consequentemente, na sua formação profissional. Entendemos que a negociação e a construção de identidades estão relacionadas a um determinado espaço e tempo histórico em que ocorrem as interações discursivas e ações sociais, não apresentando, porém, uma ordem cronológica de desenvolvimento.

Na busca por uma tentativa de compreender melhor como se dá o desenvolvimento profissional de professores, evidenciamos a importância de se dar espaço na academia para se tratar de fatores emocionais, sociais e identitários que influenciam na formação do professor e no processo de ensino e aprendizagem de línguas. Diante dessa necessidade, ressaltamos a relevância da disciplina Estágio Curricular Supervisionado na formação da identidade do professor-aprendiz. Essa identidade deve e é construída ao longo de todo o curso, ganhando mais intensidade quando os professoresaprendizes se deparam com os contextos futuros nos quais irão atuar, na realização de estágios de observação e regência de aulas, cabendo à disciplina de Estágio papel fundamental no que se refere às questões de identidade e aos fatores a ela relacionados.

Torna-se necessário, portanto, a revisão de currículos de formação de professores de línguas, ou mais especificamente, dos cursos de Licenciatura 
em Letras no nosso país. Deve haver espaço para práticas que priorizem o professor em formação, tentando compreendê-lo por meio de estudos do processo de (re)construção de identidades. Para tanto, seria desejável criar condições para uma aproximação e relação de interdependência entre todos os envolvidos no processo: professor-formador, professor da escola campo de estágio e professores em formação, de forma a priorizar uma formação construtiva, reflexiva, colaborativa, que não esteja preocupada em ensinar como ser um professor, mas que busque desenvolver o sentido de ser professor.

\section{Referências}

ALMEIDA FILHO, J. C. P. Dimensões comunicativas no ensino de línguas. 3. ed. Campinas: Pontes, 1993.

ALMEIDA FILHO, J. C. P. (Org.). Competências de aprendizes e professores de linguas. Campinas: Pontes, 2014.

ALSUP, J. Teacher identity discourses: negotiating personal and professional spaces. Mahwah, NJ: Lawrence Erlbaum, 2006.

ANDRÉ, M. E. D. A. Diferentes tipos de pesquisa qualitativa. In: ANDRÉ, M. E. D. A. Etnografia da prática escolar. 4. ed. Campinas: Papirus, 2000.

ANDRÉ, M. E. D. A. Estudo de caso em pesquisa e avaliação educacional. Brasília: Liber Livro, 2005.

ARAGÃO, R. Cognição, emoção e reflexão na sala de aula: por uma abordagem sistêmica do ensino/aprendizagem de inglês. Revista Brasileira de Lingüistica Aplicada, v. 5, n. 2, p. 101-120, 2005.

BARCELOS, A. M. F. Metodologia de pesquisa das crenças sobre aprendizagem de línguas: estudo da arte. Revista Brasileira de Lingüistica Aplicada, v. 1, n. 1, p. 71-92, 2001.

BARCELOS, A. M. F. Crenças sobre aprendizagem de línguas, linguística aplicada e ensino de línguas. Linguagem \& Ensino, v. 7, n. 1, p. 123-156, 2004. 
BARCELOS, A. M. F. Cognição de professores e alunos: tendências recentes na pesquisa de crenças sobre ensino e aprendizagem de línguas. In: BARCELOS, A. M. F.; VIEIRA-ABRAHÃO, M. H. (Org.). Crenças e ensino de línguas: foco no professor, no aluno e na formação de professores. Campinas: Pontes, 2007a. p. 15-41.

BARCELOS, A. M. F. Reflexões acerca da mudança de crenças sobre ensino e aprendizagem de línguas. Revista Brasileira de Linguistica Aplicada, v. 7, n. 2, p. 109-138, 2007b. Disponível em: <http://bit.ly/2AmDZFs>. Acesso em: 04 nov. 2013.

BARCELOS, A. M. F. Desvelando a relação entre crenças sobre ensino e aprendizagem de línguas, emoções e identidades. In: GERHARDT, M. A. A. et al. Linguística aplicada e ensino: língua e literatura. Campinas, 2013.

BORG, S. Language Teacher Cognition. In: BURNS, A.; RICHARDS, J. C. (Ed.). The Cambridge Guide to Second Language Teacher Education. Cambridge: University Press, 2009. p. 163-171.

CELANI, M. A. A. Perguntas ainda sem resposta na formação de professores de línguas. In: GIMENEZ, T.; GÓES MONTEIRO, M. C. (Org.). Formação de professores de línguas na América Latina e transformação social. v. 4. Campinas: Pontes, 2010. p. 57-67.

CLARKE, M. Language teacher identities: co-constructing discourse and community. Clevedon: Multilingual Matters, 2008.

COELHO, H. S. H. Experiências, emoções e transformações na educação continuada. 2011. Tese (Doutorado em Estudos Linguísticos) - Universidade Federal de Minas Gerais, Belo Horizonte.

CORACINI, M. J. R. F. Língua estrangeira e língua materna: uma questão de sujeito e identidade. In: CORACINI, M. J. R. F. (Org.). Identidade e discurso: (des)construindo subjetividades. Campinas: Unicamp, 2003. p. 139-159.

ERICKSON, F. Qualitative methods in research on teaching. In: WITTROCK, M. C. (Ed.). Handbook of research teaching. New York: MacMillan, 1986. 
FABRÍCIO, B. F. Narrativização da experiência: o triunfo da ordem sobre o acaso. In: MAGALHÃES, I.; GRIGOLETTO, M; CORACINI, M. J. (Org.). Práticas identitárias: língua e discurso. São Carlos: Claraluz, 2006. p. 191-209.

FAIRCLOUGH, N. Critical discourse analysis and the marketization of public discourse. The Universities. Discourse and Society, v. 4, n. 2, p. 133-168, 1993.

GERHARDT, A. F. L. M.; AMORIM. M. A. e CARVALHO, A. M. (Org). Linguística aplicada e ensino: língua e literatura. Campinas, 2013.

GIL, G. Mapeando os estudos de formação de professores de línguas no Brasil. In: FREIRE, M. M.; VIEIRA-ABRAHÃO, M. H.; BARCELOS, A. M. F. (Org.). Lingüistica aplicada e contemporaneidade. Campinas: ALAB; Pontes, 2005.

GRANT, C. A.; ZEICHNER, K. M. Inservice support for first-year teachers: the state of the scene. Journal of Research and Development in Education, n. 1, p. 99-111, 1981.

GRIGOLETTO, M. Representação, identidade e aprendizagem de língua estrangeira. In: CORACINI, M. J. (Org.). Identidade e discurso: (des)construindo subjetividades. Campinas: Unicamp, 2003. p. 223-235.

JOHNSON, K. E. The Sociocultural turn and its challenges for L2 teacher education. TESOL Quarterly, v. 4, n. 40, p. 235-257, 2006.

JOHNSON, K. E. Second language teacher education: a sociocultural perspective. New York: Routledge, 2009.

JOHNSON, K. E.; GOLOMBEK, P. R. The transformative power of narrative in second language teacher education. TESOL Quarterly, n. 40, p. 1-22, 2011.

LEFFA, V. J. Identidade e aprendizagem de línguas. In: SILVA, K. A. et al. (Org.). A formação de professores de línguas-novos olhares. v. 2. São Paulo: Pontes, 2012. p. $51-81$. 
MAHER, T. M. Formação de professores indígenas: uma discussão introdutória. In: GRUPIONI, L. D. B. (Org.). Formação de professores indigenas: repensando trajetórias. Brasília: MEC; SECAD, 2006. p. 11-38.

MAHER, T. M. Políticas linguísticas e políticas de identidade: currículo e representações de professores indígenas na Amazônia Ocidental brasileira. Currículo sem Fronteiras, v. 10, p. 33-48, 2010.

MATURANA, H. Emoções e linguagem na educação e na política. Belo Horizonte: UFMG, 2005.

MOITA LOPES, L. P. Oficina de lingüistica aplicada. Campinas: Mercado de Letras, 1996.

MOITA LOPES, L. P. Discursos de identidade em sala de aula de leitura de L1: a construção da diferença. In: SIGNORINI, I. (Org.). Lingua(gem) e identidade: elementos para uma discussão no campo aplicado. Campinas: Mercado de Letras, 2002a. p. 303-330.

MOITA LOPES, L. P. Identidades fragmentadas. Campinas: Mercado de Letras, 2002b.

MOITA LOPES, L. P.; BASTOS, L. C. Identidades: recortes multi e interdisciplinares. Campinas: Mercado de Letras, 2002c.

MORAES, R. B. de. Re-storying teaching experience in a continuing teacher education project. In: BARCELOS, A. M. F.; COELHO, H. S. H. (Org.). Emoçöes, reflexões e (trans)form (ações) de alunos, professores e formadores de professores de linguas. Campinas: Pontes, 2010. p. 155-176.

MORGAN, B. Identity and intonation: Linking dynamic processes in the ESL classroom. TESOL Quarterly, v. 31, n. 3, 431-450, 1994.

NORTON, P. B. Identity and language learning: gender, ethnicity and educational change. Edinburgh: Pearson Education, 2000.

NORTON, P. B. Towards a model of critical language teacher education. Language Issues, v. 1, n. 17, p. 12-17, 2005. 
PIMENTA, S. G.: GHEDIN, E. (Org.). Professor reflexivo no Brasil: gênese e crítica de um conceito. São Paulo: Cortez, 2002.

RAJAGOPLAN, K. L. Identity discourse and the politics of representation. Conexão Letras, v. 2, p. 10-15, 2006.

REIS, D. S. I'm not alone: empowering non-native English-speaking teachers to challenge the native speaker myth. In: JOHNSON, K. E.; GOLOMBEK, P. R. (Ed.). Research on second language teacher education: a sociocultural perspective on professional development. New York; London: Routledge, 2011. p. 31-49.

ROGERS, D. L.; BABINSKI, L. M. From isolation to conversation: supporting new teachers' development. Albany: State University of New York Press, 2002.

ROSIEK, J. Emotional scaffolding: an exploration of teacher knowledge at the intersection of student emotion and subject matter content. The Journal of Teacher Education, v. 54, n. 5, p. 399-412, 2003.

SCHERER, A. E.; MORALES, G.; LECLERQ, H. Palavras de intervalo no decorrer da vida ou por uma política imaginária da identidade e da linguagem. In: CORACINI, M. J. (Org.). Identidade e discurso: (des)construindo subjetividades. Campinas: UNICAMP; Chapecó: Argos Universitária, 2003. p. 23-36.

SIGNORINI, I. Gêneros catalisadores: letramento \& formação do professor. São Paulo: Parábola, 2006.

SILVA, W. R.; MELO, L. C. Práticas escolares de linguagem propostas em estágio supervisionado de ensino de língua inglesa. Revista do GELNE, v. 12, n. 2, p. 72-82, 2010.

VARGHESE, M. et al. Theorizing language teacher identity: Three perspectives and beyond. Journal of Language, Identity, and Education, v. 6, n. 4, p. $21-44,2005$. 
VIEIRA-ABRAHÃO, M. H. Conflitos e incertezas do professor de língua estrangeira na renovação de sua prática de sala de aula. 1996. Tese (Doutorado em Linguística Aplicada) - Universidade Estadual de Campinas, Campinas.

VIEIRA-ABRAHÃO, M. H. A Formação inicial e o desenvolvimento profissional do professor de línguas estrangeiras: práticas e pesquisas. Horizontes de Lingüistica Aplicada, Brasília, v. 5, n. 2, p. 8-23, 2006 a.

VIEIRA-ABRAHÃO, M. H. The construction of theoretical and practical knowledge in initial teacher education. Profile: issues in teacher's professional development, n. 7, p. 87-99, 2006b.

VIEIRA-ABRAHÃO, M. H. A formação do professor de línguas de uma perspectiva sociocultural. Signum: Estudos da Linguagem, Londrina, v. 15, n. 2, p. 457-480, 2012. Disponível em: <http://bit.ly/2j9VFuA>. Acesso em: 14 ago. 2016.

VIEIRA-ABRAHÃO, M. H. Sessões colaborativas na formação inicial e em serviço de professores de inglês. Horizontes em Linguística Aplicada, a. 13, n. 1, p. 15-39, 2014.

VIGOTSKI, L. V. Pensamento e linguagem. Trad. Jefferson Luiz Camargo. São Paulo: Martins Fontes, 1987.

VIGOTSKI, L. V. A formação social da mente. 6. ed. Trad. José Cippola Neto et al. São Paulo: Martins Fontes, 1999.

VIGOTSKI, L. V. A construção do pensamento e da linguagem. 2. ed. Trad. Paulo Bezerra. São Paulo: WMF Martins Fontes, 2010.

ZEMBYLAS, M. Discursive practices, genealogies, and emotional rules: a poststructuralist view on emotion and identity in teaching. Teaching and Teacher Education, v. 21, p. 935-948, 2005.

Recebido em: 14/10/2016

Aceito em: 15/08/2017 